\title{
Molecular Identification, Antifungal Susceptibility, and Geographic Origin of Clinical Strains of Sporothrix schenckii Complex in Mexico
}

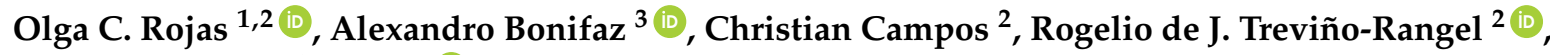 \\ Rafael González-Álvarez 4 (i) and Gloria M. González ${ }^{2, *}$ \\ 1 Departamento de Ciencias Básicas, Vicerrectoría de Ciencias de la Salud, Universidad de Monterrey, \\ San Pedro Garza García, Monterrey 66238, Mexico; olga.rojas@udem.edu \\ 2 Departamento de Microbiología, Facultad de Medicina, Universidad Autónoma de Nuevo León, \\ Monterrey 64460, Mexico; cliscamposc@gmail.com (C.C.); roghe24@gmail.com (R.d.J.T.-R.) \\ 3 Departamento de Micología \& Servicio de Dermatología, Hospital General de México, México City 06726, \\ Mexico; a_bonifaz@yahoo.com.mx \\ 4 Departamento de Genética y Medicina Genómica, Facultad de Medicina, Universidad Autónoma de \\ Guadalajara, Zapopan 45129, Mexico; rgonzaleza5@hotmail.com \\ * Correspondence: gmglez@yahoo.com.mx; Tel.: +52-81-8329-4217
}

Received: 14 June 2018; Accepted: 18 July 2018; Published: 20 July 2018

\begin{abstract}
Sporotrichosis is a subcutaneous mycosis caused by Sporothrix schenckii complex. The disease has been reported worldwide. However, the incidence of the etiological agent varies in its geographic distribution. We studied 39 clinical isolates of Sporothrix schenckii from diverse regions in Mexico, collected from 1998 to 2016. Molecular identification was performed by sequence analysis of the partial calmodulin gene. In vitro antifungal susceptibility to amphotericin B (AMB), itraconazole (ITC), voriconazole (VRC), posaconazole (PSC), fluconazole (FLC), terbinafine (TRB), caspofungin (CSF), anidulafungin (ANF), and micafungin (MCF) was evaluated. Thirty-eight isolates of S. schenckii complex were divided into five supported clades in a phylogenetic tree. The predominant clinical form was lymphocutaneous $(92.3 \%)$, fixed cutaneous $(5.1 \%)$, and disseminated $(2.5 \%)$. Terbinafine exhibited the best in vitro antifungal activity, while fluconazole was ineffective against Sporothrix schenckii complex. Our results showed diverse geographic distribution of clinical isolates in eight states; definitive identification was done by CAL gen PCR-sequencing. In Mexico, S. schenckii is considered to be an etiological agent of human sporotrichosis cases, and lymphocutaneous is the most prevalent form of the disease. This study revealed four clades of $S$. schenckii sensu stricto by phylogenetic analysis. Furthermore, we report one case of $S$. globosa isolated from human origin from the North of Mexico.
\end{abstract}

Keywords: Sporothrix schenckii; Sporothrix globosa; CAL gen; clinical; origin; Mexico

\section{Introduction}

Human sporotrichosis is a subcutaneous mycosis caused by dimorphic fungi Sporothrix schenckii species complex, which comprises four species of clinical importance: S. brasiliensis, S. globose, S. luriei, and S. schenckii sensu stricto [1]. Sporotrichosis has been reported to be endemic in areas of Latin America, South Africa, India, and Japan. In Latin America, the endemic areas are restricted to Peru, Brazil, Mexico, Uruguay, Costa Rica, Guatemala, Colombia, and Venezuela. Sporotrichosis has emerged as a major fungal infection over the last two decades due to changes in epidemiology distribution, taxonomic evolution, and multiple outbreaks. Sporotrichosis in Mexico occurs primarily in regions with a tropical and humid climate. While cases have been reported throughout the country, the highest 
prevalence has been noted in two zones: the states of Jalisco and Puebla [2]. Sporothrix species differ in their geographical distribution. In this sense, S. brasiliensis is an emerging species restricted to Brazil, and it is highly pathogenic to humans and animals [3]. S. globosa is distributed worldwide, including Europe, the United States, South America, and Asia [2]. A study of clinical isolates from Northeast China described two clades for S. globosa—subclade I and subclade II—and found they were not related to geography [4]. In another study from Japan, S. globosa was divided into two subclades and S. schenkii sensu stricto strains into three subclades [5]. Sporothrix luriei has been reported in three human infections in Africa, Italy, and India [2]. Y. Zhang et al. showed five supported subgroups of S. schenckii by CAL gen, which was also recognizable in AFLP data [6]. Molecular and phylogenetic analyses of S. schenckii complex revealed some genetic diversity $[7,8]$. These species have distinct virulence profiles, and they are rarely identified from clinical origins [5]. The different clinical forms are associated with different species [4]. Sporotrichosis, restricted to skin, is treated by systemic chemotherapy with potassium iodide. Other drugs commonly used are itraconazole for lymphocutaneous infections and amphotericin B for disseminated cutaneous recurrent, extracutaneous, and lymphocutaneous infection $[5,8]$. The variability in therapeutic efficacy and in vitro activity demonstrated in different studies is attributed to the fact that $S$. schenckii is a complex of different species [9-11]. Herein, we present Mexican clinical isolates identified by phenotypic characterization and partial sequences of the CAL gen. The demographic characteristics of all stains from diverse regions in Mexico is shown. The antifungal susceptibility patterns of these isolates were also determined in this study.

\section{Materials and Methods}

Thirty-nine clinical isolates were collected between 1998 and 2016 from different Mexican regions (Table 1). All isolates were obtained from a collection of the Microbiology Department of the School of Medicine, Universidad Autónoma de Nuevo León. The isolates were previously identified as S. schenckii by morphology as well as macroscopic and microscopic features. All isolates had the data regarding the origin of patients and type of lesion.

Table 1. Data of clinical human sporotrichosis and molecular analysis used in this study.

\begin{tabular}{|c|c|c|c|c|c|}
\hline Strain & $\begin{array}{l}\text { Species (Molecular } \\
\text { Identification) }\end{array}$ & Lesion Type & Origin from Mexico & $\begin{array}{l}\text { GenBank Accession } \\
\text { No. CAL Gen }\end{array}$ & $\begin{array}{c}\text { Variant in } \\
\text { Phylogenetic Tree }\end{array}$ \\
\hline $98-164$ & Sporothrix schenckii & Lymphocutaneous & Mexico City & MF948670 & 1 \\
\hline $98-578$ & Sporothrix schenckii & Lymphocutaneous & Mexico City & MF948671 & 1 \\
\hline 99-098 & Sporothrix schenckii & Lymphocutaneous & Mexico City & MF948672 & 2 \\
\hline $99-689$ & Sporothrix schenckii & Fixed cutaneous & Mexico City & MF948673 & 1 \\
\hline $00-45$ & Sporothrix schenckii & Lymphocutaneous & Mexico City & MF948674 & 2 \\
\hline 02-845 & Sporothrix schenckii & Lymphocutaneous & Mexico City & MF948675 & 4 \\
\hline $02-846$ & Sporothrix schenckii & Lymphocutaneous & Mexico City & MF948676 & 2 \\
\hline $02-847$ & Sporothrix schenckii & Lymphocutaneous & Mexico City & MF948677 & 2 \\
\hline $02-849$ & Sporothrix schenckii & Fixed cutaneous & Mexico City & MF948678 & 2 \\
\hline $02-850$ & Sporothrix schenckii & Lymphocutaneous & Mexico City & MF948679 & 1 \\
\hline 02-851 & Sporothrix schenckii & Lymphocutaneous & Mexico City & MF948680 & 1 \\
\hline $02-852$ & Sporothrix schenckii & Lymphocutaneous & Mexico City & MF948681 & 2 \\
\hline 03-017 & Sporothrix schenckii & Lymphocutaneous & Veracruz & MF948682 & 1 \\
\hline 03-018 & Sporothrix schenckii & Lymphocutaneous & Veracruz & MF948683 & 1 \\
\hline 06-345 & Sporothrix schenckii & Lymphocutaneous & San Luis Potosi & MF948684 & 2 \\
\hline 06-743 & Sporothrix schenckii & Lymphocutaneous & San Luis Potosi & MF948685 & 4 \\
\hline 07-089 & Sporothrix schenckii & Lymphocutaneous & Coahuila & MF948686 & 2 \\
\hline 07-956 & Sporothrix schenckii & Lymphocutaneous & San Luis Potosi & MF948687 & 3 \\
\hline 08-345 & Sporothrix schenckii & Lymphocutaneous & Coahuila & MF948688 & 2 \\
\hline 08-390 & Sporothrix schenckii & Lymphocutaneous & Mexico City & MF948689 & 1 \\
\hline 08-624 & Sporothrix schenckii & Lymphocutaneous & Nuevo Leon & MF948690 & 3 \\
\hline 09-321 & Sporothrix schenckii & Lymphocutaneous & Mexico City & MF948691 & 3 \\
\hline 11-131 & Sporothrix schenckii & Lymphocutaneous & Puebla & MF948692 & 1 \\
\hline $11-567$ & Sporothrix schenckii & Lymphocutaneous & Nuevo Leon & MF948693 & 1 \\
\hline $12-078$ & Sporothrix schenckii & Lymphocutaneous & Oaxaca & MF948694 & 1 \\
\hline $13-670$ & Sporothrix globosa & Lymphocutaneous & Nuevo Leon & MF948695 & 5 \\
\hline $14-821$ & Sporothrix schenckii & Lymphocutaneous & Puebla & MF948696 & 2 \\
\hline $14-822$ & Sporothrix schenckii & Lymphocutaneous & Puebla & MF948697 & 1 \\
\hline
\end{tabular}


Table 1. Cont.

\begin{tabular}{cccccc}
\hline Strain & $\begin{array}{c}\text { Species (Molecular } \\
\text { Identification) }\end{array}$ & Lesion Type & Origin from Mexico & $\begin{array}{c}\text { GenBank Accession } \\
\text { No. CAL Gen }\end{array}$ & $\begin{array}{c}\text { Variant in } \\
\text { Phylogenetic Tree }\end{array}$ \\
\hline $14-823$ & Sporothrix schenckii & Lymphocutaneous & Puebla & MF948698 & 1 \\
$14-824$ & Sporothrix schenckii & Lymphocutaneous & Oaxaca & MF948699 & 1 \\
$16-09$ & Sporothrix schenckii & Lymphocutaneous & Oaxaca & MF948700 & 3 \\
$16-020$ & Sporothrix schenckii & Lymphocutaneous & Oaxaca & MF948701 & 4 \\
$16-021$ & Sporothrix schenckii & Disseminated & Oaxaca & MF948702 & 3 \\
$16-022$ & Sporothrix schenckii & Lymphocutaneous & Oaxaca & MF948703 & 1 \\
$16-230$ & Sporothrix schenckii & Lymphocutaneous & Mexico City & MF948704 & 1 \\
$16-236$ & Sporothrix schenckii & Lymphocutaneous & Mexico City & MF948705 & 1 \\
$16-237$ & Sporothrix schenckii & Lymphocutaneous & Mexico City & MF948706 & 1 \\
$16-678$ & Sporothrix schenckii & Lymphocutaneous & Jalisco & MF948707 & 1 \\
$16-679$ & Sporothrix schenckii & Lymphocutaneous & Jalisco & MF948708 & 1 \\
\hline
\end{tabular}

\subsection{Phenotypic Characterization}

Thirty-nine clinical isolates were re-examined by macroscopic and microscopic studies according to Marimon criteria [12]. Macroscopic characteristics of colonies were studied by culturing isolates on potato dextrose agar (PDA); plates were incubated at 30,35 , and $37^{\circ} \mathrm{C}$. Petri dishes were inoculated with colonies of each fungus and $10 \mu \mathrm{L}$ of conidial suspension adjusted to $1 \times 10^{7}$ cells $/ \mathrm{mL}$ for each isolate. After 14 and 21 days, colony diameters were measured in duplicate. Microscopic features of conidia were determined by slide cultures made on PDA after 12-15 days of incubation in the dark and in a humid chamber. Coverslips were mounted in lactophenol cotton blue. The slides were examined under a Nikon Eclipse 50i microscope fitted with a Nikon digital sight DS-2Mv camera. The conidia were measured. The ability of all isolates to reverse to yeast-like cells at $37{ }^{\circ} \mathrm{C}$ was performed on brain heart infusion (BHI) with blood for 9 days. Carbohydrate assimilation was tested using API 20C AUX strips (bioMerieux, Mexico City, Mexico) [13].

\subsection{Antifungal Susceptibility}

The antifungal susceptibility test was performed according to the Clinical and Laboratory Standards Institute (CLSI) M38-A2 broth microdilution method [14]. Briefly, a drug stock solution was prepared by dissolving an appropriate amount of amphotericin B (AMB; Bristol Myers Squibb, Princeton, NJ, USA), itraconazole (ITC; Wako Pure Chemicals, Osaka, Japan), voriconazole (VRC, Pfizer, Inc., New York, NY, USA), posaconazole (PSC; Merck, Rahway, NJ, USA), fluconazole (FLC; Pfizer, Inc, Amoise, France), terbinafine (TRB; Novartis, Mexico City, Mexico), caspofungin (CSF; Merk, Rahway, NJ, USA), anidulafungin (ANF; Ben Venve, Northfield Road Bedfor, OH, USA), and micafungin (MCF; Astellas, Tokyo, Japan). The antifungal concentration ranges were adjusted as follows: 0.125 to $16 \mu \mathrm{g} / \mathrm{mL}$ for AMB, ITC, and VRC; from 0.0313 to $16 \mu \mathrm{g} / \mathrm{mL}$ for PSC; from 0.125 to $64 \mu \mathrm{g} / \mathrm{mL}$ for FLC; from 0.004 to $2 \mu \mathrm{g} / \mathrm{mL}$ for TRB; and from 0.015 to $8 \mu \mathrm{g} / \mathrm{mL}$ for CFS, ANF, and MCF. The isolates were cultivated on PDA for 7 days at $30^{\circ} \mathrm{C}$; an inoculum was prepared as recommended by the CLSI and adjusted $(80-82 \% \mathrm{~T}, \lambda=530 \mathrm{~nm})$. The microplates were incubated at $30{ }^{\circ} \mathrm{C}$ and read at $72 \mathrm{~h}$. The minimal inhibitory concentration (MIC) endpoint for the triazoles, AMB, MCF, ANF, and TRB was defined as the lowest concentration that produces complete inhibition of growth; for FLC and CSF, it was defined as the lowest drug concentration able to inhibit $50 \%$ of visible fungal growth. For quality control of antifungal susceptibilities testing, Candida albicans ATCC 90028, Candida parapsilosis ATCC 22019, and Paecilomyces variotii MYA 3630 were used.

\subsection{Molecular Identification}

Genomic DNA of isolates was extracted from the mycelial phase of the strain on PDA plates at $30{ }^{\circ} \mathrm{C}$ for 10 days. DNA was extracted twice with phenol-chloroform and isoamyl-alcohol according to our previous study [15]. Amplification of the partial calmodulin (CAL) gene was performed using the degenerated primers sense CL1 5'-GA(GA)T(AT)CAAGGAGGCCTTCTC-3' and antisense CL2A 
5'-TTTTTGCATCATGAGTTGGAC-3' [16]. Amplifications were performed in standard condition: one initial cycle of $3 \mathrm{~min}$ at $94{ }^{\circ} \mathrm{C}$ followed by 30 cycles of $30 \mathrm{~s}$ at $94{ }^{\circ} \mathrm{C}, 50 \mathrm{~s}$ at $53.4{ }^{\circ} \mathrm{C}, 1 \mathrm{~min}$ at $72{ }^{\circ} \mathrm{C}$, and a single extension cycle at $72{ }^{\circ} \mathrm{C}$ for $5 \mathrm{~min}$. Amplicons were purified using QIAquick (Qiagen, Hilden, Germany) and sequenced in a Genetic Analyzer 3100 (Applied Biosystems, Foster City, CA, USA). Sequences were finally edited in Codon code aligner 4.2.7 software and compared in NCBI GenBank sequences using the BLAST program (http:/ / www.ncbi.nlm.nih.gov / BLAST) to determine their identity. Alignments were performed using Clustal Omega software [17]. A phylogenetic tree was built using the neighbor-joining (NJ) method and a bootstrap analysis [18] of 1000 replicas implemented in MEGA 6.06 software [19]. The phylogenetic tree was constructed with partial calmodulin gene sequences encoding calmodulin-encoding gene [18,19]. The analysis of Sporothrix CAL-related sequences was performed using the sequences obtained in this work (Table 1) and those retrieved from Genbank—Sporothrix schenckii (KT427643 and KT427645), Sporothrix globosa (KT427636 and KP101459), Sporothrix brasiliensis (KJ769111), and Sporothrix luriei (KT427639); Sporothrix mexicana (KR269843) was used as the out-group.

\section{Results}

\subsection{Phenotypic Characterization}

A total of 39 clinical isolates from the Microbiology Department collection were studied. The phenotypic characteristic studied as macroscopic morphologies of all isolates were variable after 21 days of incubation. The colonies were initially white/cream colored and later turned brown, then dark brown and with a mixed color on PDA (Figure 1). The colony diameters on PDA after 21 days of incubation attained $30.9 \pm 5.0 \mathrm{~mm}$ at $30^{\circ} \mathrm{C}, 11.5 \pm 5.3 \mathrm{~mm}$ at $35^{\circ} \mathrm{C}$, and $5 \pm 1.8 \mathrm{~mm}$ at $37^{\circ} \mathrm{C}$. Microscopic features, conidium size, thermotolerance, dimorphism, and the urease test were performed. All isolates showed temperature dimorphism and were urease test positive; conidia were hyaline, ovoid, thick-walled, and almost all isolates were similar. Only three isolates were misidentified as S. globosa by microscopic features. They exhibited intercalary or terminal conidia formed by sympodial growth from differentiated conidiophores; the conidia were hyaline to slightly pigmented. Sessile conidia were sub globosa and dematiaceous (Figure 2). A carbohydrate assimilation test for sucrose and raffinose was positive for all isolates except one (MF948695), which was negative for raffinose.
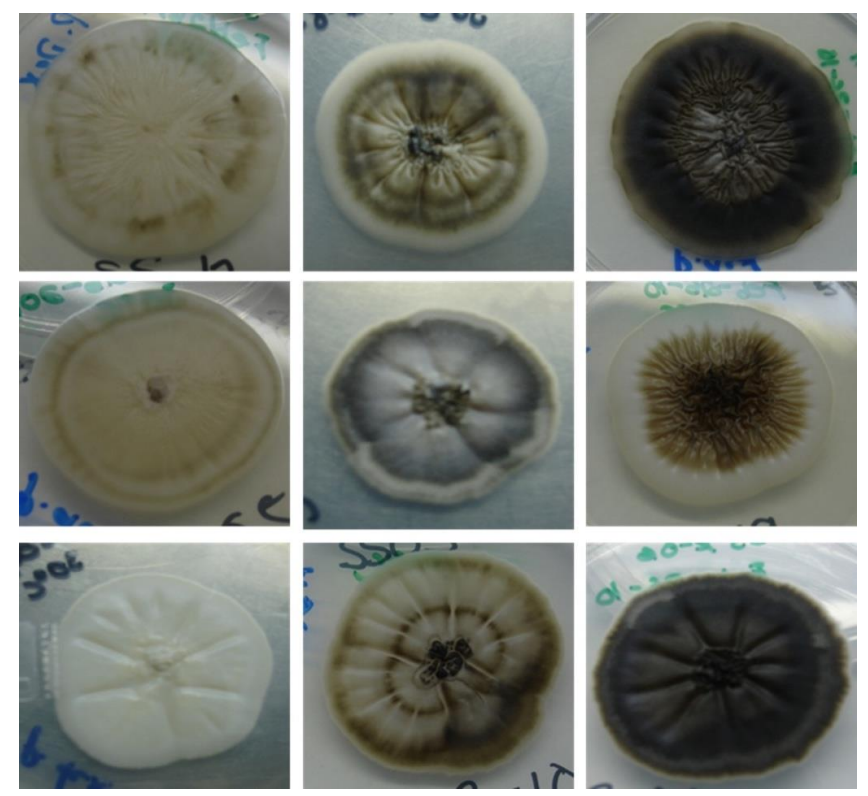

Figure 1. Representative images of colonial morphology of the Sporothrix schenckii complex clinical isolates evaluated in this study. 


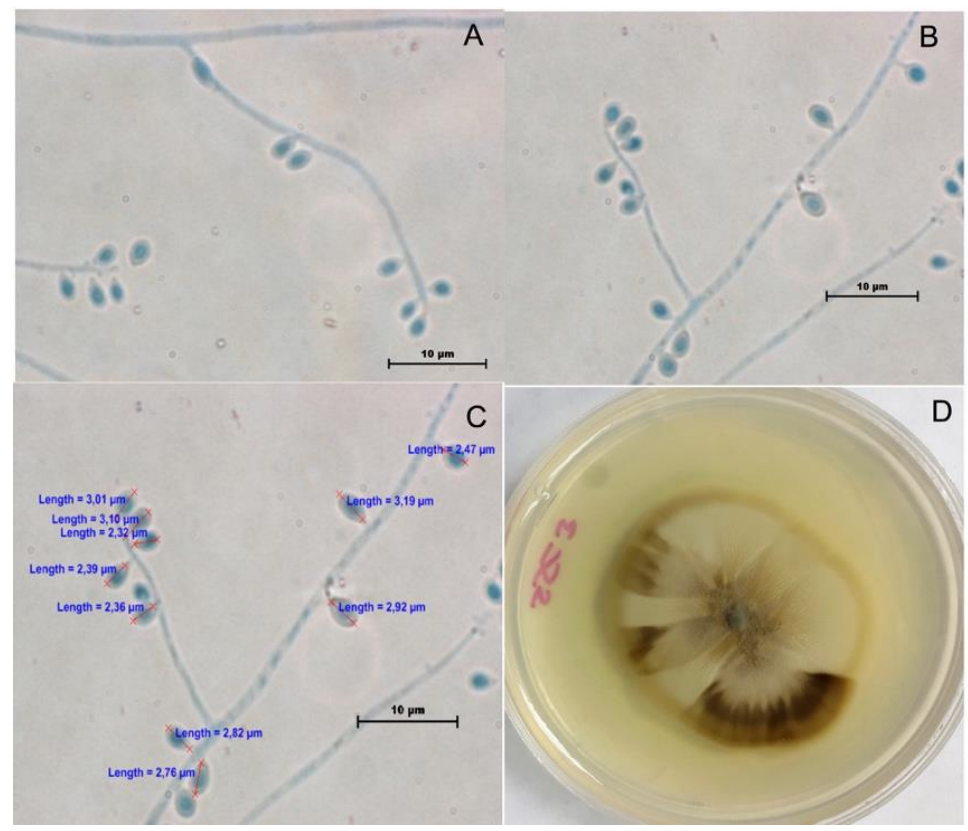

Figure 2. S. globosa morphological characteristics. (A) Hyphae, conidiophore, and sessile conidia $(200 \times)$; (B) Sessile conidia $(200 \times)$; (C) Morphometric analysis $(200 \times)$; (D) Colony on potato dextrose agar (PDA) at $30^{\circ} \mathrm{C}$ in 21 days.

\subsection{Antifungal Susceptibility}

Antifungal susceptibility testing results are presented in Table 2. Nine drugs were tested. The antifungal susceptibilities (MIC ranges) were as follows: $\mathrm{AMB}=0.5-4 \mu \mathrm{g} / \mathrm{mL}$, ITC $=0.125-2 \mu \mathrm{g} / \mathrm{mL}, \mathrm{VRC}=0.5-8 \mu \mathrm{g} / \mathrm{mL}$, PSC $=0.5-8 \mu \mathrm{g} / \mathrm{mL}, \mathrm{FLC}>64 \mu \mathrm{g} / \mathrm{mL}, \mathrm{TRB}=0.06-1 \mu \mathrm{g} / \mathrm{mL}$, $\mathrm{CSF}=0.5-8 \mu \mathrm{g} / \mathrm{mL}, \mathrm{ANF}=0.25-8 \mu \mathrm{g} / \mathrm{mL}$, and MCF $=0.5-8 \mu \mathrm{g} / \mathrm{mL}$. Terbinafine showed the best in vitro antifungal activity, while fluconazole was ineffective against $S$. schenckii.

Table 2. The results of $\mathrm{MIC}_{50}$ and $\mathrm{MIC}_{90}$ of nine antifungal drugs against 39 isolates of $S$. schenckii complex.

\begin{tabular}{ccccc}
\hline Antifungal & GM & Range $(\mu \mathrm{g} / \mathbf{m L})$ & MIC $_{\mathbf{5 0}}(\mu \mathrm{g} / \mathbf{m L})$ & MIC $_{\mathbf{9 0}}(\mu \mathrm{g} / \mathbf{m L})$ \\
\hline Amphotericin B AMB & 2.554 & $0.5-4$ & 4 & 4 \\
Itraconazole ITC & 4 & $0.125-2$ & 4 & 8 \\
Voriconazole VRC & 2.946 & $0.5-8$ & 2 & 4 \\
Posaconazole PSC & 1.769 & $0.5-8$ & 1 & 8 \\
Fluconazole FLC & $>64$ & $64->64$ & 64 & $>64$ \\
Terbinafine TRB & 0.374 & $0.06-1$ & 0.5 & 1 \\
Caspofungin CSF & 1.959 & $0.5-8$ & 2 & 4 \\
Anidulafungin ANF & 2.083 & $0.25-8$ & 2 & 4 \\
Micafungin MCF & 2.402 & $0.5-8$ & 2 & 4
\end{tabular}

$\mathrm{MIC}_{50}-\mathrm{MIC}_{90}$ : minimal inhibitory concentration at which $50 \%$ and $90 \%$ of microorganisms are inhibited. GM: geometric mean.

\subsection{Molecular Identification}

Molecular identification was done by CAL gen PCR-sequencing. Thirty-eight were identified as Sporothrix schenckii and one as Sporothrix globosa, which came from the city of General Zaragoza, Nuevo León and showed a lymphocutaneous clinical presentation. Their geographical origin was as follows: Mexico City (43.5\%), Oaxaca (15.3\%), Puebla (10.2\%), Nuevo León (7.6\%), San Luis Potosí (7.6\%), Veracruz (5.1\%), Coahuila (5.1\%), and Jalisco (5.1\%). The most prevalent clinical presentation was lymphocutaneous sporotrichosis $(92.3 \%)$, followed by fixed cutaneous sporotrichosis $(5.1 \%)$, and one case of disseminated sporotrichosis (2.5\%) (Table 1). Genetic identification was done using a 
fragment of the CAL gene, 785 base pairs (bp). Our results showed diverse geographic distribution of clinical isolates in eight states. Thirty-nine isolates were divided into five supported clades. Clade I consisted of 20 isolates: Mexico City (9), Puebla (3), Oaxaca (3), Jalisco (2), Veracruz (2), and Nuevo León (1). Clade II consisted of 10 isolates: Mexico City (6), Coahuila (2), Puebla (1), and San Luis Potosi (1). Clade III consisted of five isolates: Oaxaca (2), Puebla (1), San Luis Potosi (1), Nuevo Leon (1). Clade IV consisted of three isolates: Mexico City (1), Oaxaca (1), and San Luis Potosi (1). Clade V consisted of one isolate from Nuevo Leon.

BLAST analysis showed the following identity: Clade (I) KT427643 = MF948670, MF948671, MF948673, MF948679, MF948680, MF948682, MF948683, MF948689, MF948692, MF948693, MF948694, MF948697, MF948698, MF948699, MF948703, MF948704, MF948705, MF948706, MF948707, and MF948708; Clade (II) MF948696 = MF948672, MF948674, MF948676, MF948677, MF948678, MF948681, MF948684, MF948686, and MF948688; Clade (III) MF948700 = MF948687, MF948690, MF948691, and MF948702; Clade (IV) MF948701 = MF948675 and MF948685; and Clade (V) MF948695 $=$ KT427636 and KP101459. Thus, there were only five genetic clades according to the CAL gene- $\mathrm{I}$, II, III, IV, and V. The clade arrangement in a lineage-specific manner is shown in Figure 3. From top to bottom, S. schenckii, S. brasiliensis, S. globosa, and S. luriei branches can be seen. Finally, S. mexicana was used as the out-group. Also to note, S. schenckii was subdivided into two subclades: (1) KT427643, MF948670, and MF948696; and (2) MF948700 and MF948701.

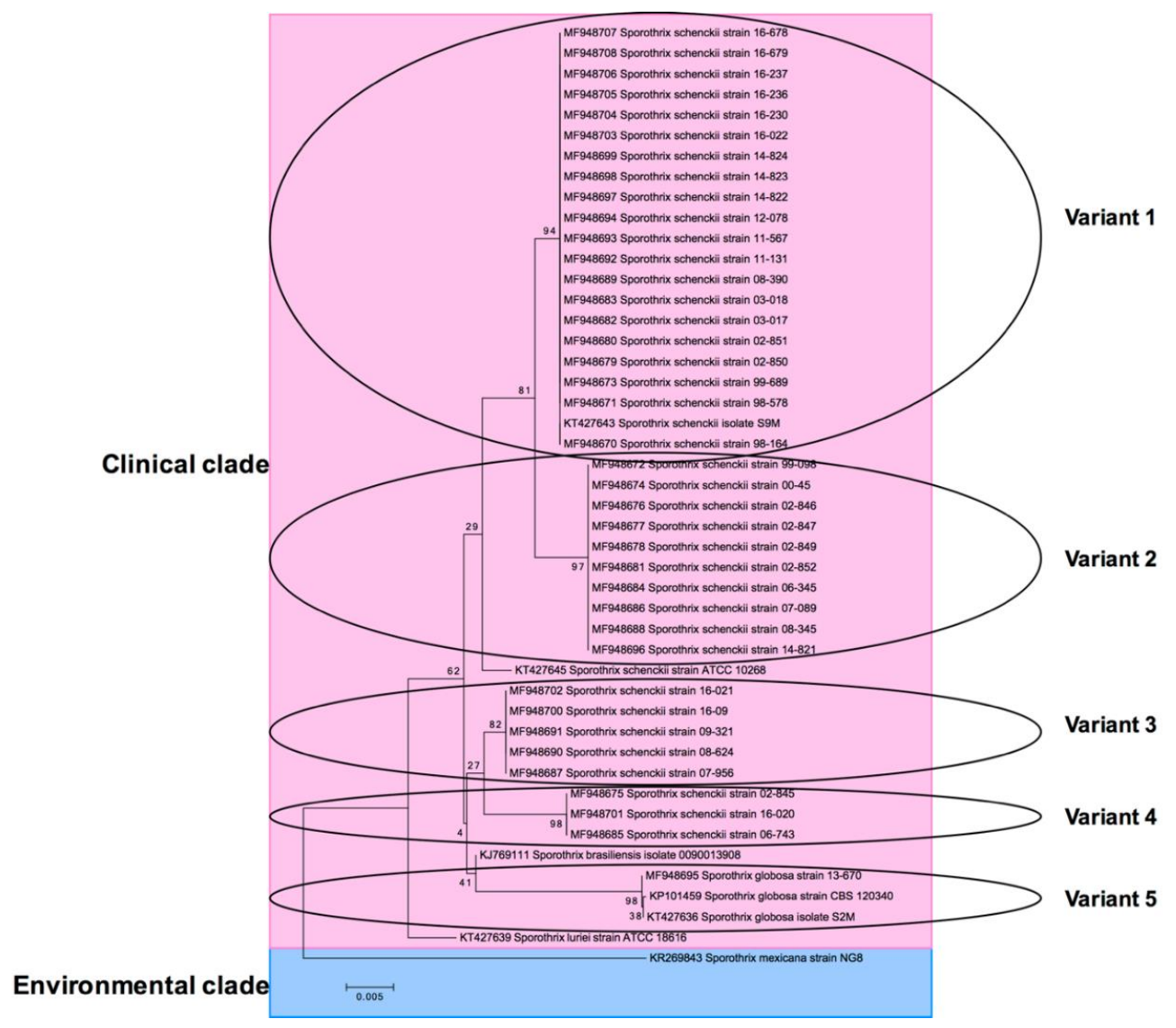

Figure 3. Phylogenetic tree of the CAL coding sequences from various fungi. The tree was built using MEGA version 6.06 by the neighbor-joining (NJ) method and further bootstrap analysis of 1000 replicas. Number on the branches indicate the bootstrap value. From the top to the bottom, clades are in linage-specific manner. Pink encompasses the clinical species, while blue is the environmental specie that was used as the out-group. Clinical clade was further divided into small subclades or variants (ovals) that correspond to the specific Sporothrix specie. Subclades did not match with geographical origin or antifungal resistance. 


\section{Discussion}

The species of Sporothrix was previously described as a single species. However, it is now recognized as $S$. schenckii complex based on phylogenetic studies using DNA sequence in specific regions of rDNA, internal transcribed spacer (ITS), calmodulin, $\beta$-tubulin, and translation elongation factor 1 genes. Calmodulin gene in particular has been widely used for taxonomy for Sporothrix species [5,10]. In our study, 39 isolates were identified by partial sequences of the calmodulin gene. The phylogenetic tree showed five main branches (variants). These variants matched with Sporothrix schenckii CAL gene sequences as expected, but their phylogenetic relationship was not related to their geographical origin. For example, variant 4 had clinical isolates from Mexico City (strain 02-845), Oaxaca (strain 16-020), and San Luis Potosi (strain 06-743). One isolate (MF948695) was clustered into the S. globosa clade. In a recent study, S. schenckii sensu stricto was divided in five subclades with calmodulin for AFLP and phylogenetic analysis of isolates from all over the world [6]. Suzuki et al., concluded that Sporothrix species have a distinct virulence profile, but there is no clear relationship between genotypes S. globosa subgroups I, II, or S. Schenckii sensu stricto and geography in Japan or clinical forms [5]. The disease is characterized by nodular cutaneous and subcutaneous lesions, which may involve the adjacent lymphangitic system. The most common clinical manifestation was lymphocutaneous in this study, which is in agreement with the literature $[4,7,11,12,20]$. The results showed that only one isolate was identified as S. globosa. This species was reported in 2006 by Marimon et al. [12]. S. globosa is the most extensively studied species, with a report on North, Central and South America, Europe, and Asia [21]. Other reports in our country have revealed two species that are etiological agents of human sporotrichosis [2,7]. However, S. schenckii sensu stricto is the most common species that causes sporotrichosis in Mexico [2]. The geographic origin of Sporothrix species in Mexico is diverse [7]. A recent study of 22 Mexican isolates found San Luis Potosi as the principal origin. This was contrary to Chakrabarti et al. who reported Puebla as a high endemic region [2]. We found that most isolates were from Mexico City, followed by Oaxaca. This does not correspond with the recent report from Rangel-Gamboa et al., which found clinical isolates from San Luis Potosi, followed by Puebla. However, the most frequent clinical manifestation was lymphocutaneous, which conformed to our finding. The distribution of $S$. globosa has been reported in many countries $[4-6,8,13,21,22]$. A few reports of clinical presentations of this species exist; most presentations were lymphocutaneous, with fixed cutaneous being a less frequent disseminated presentation $[4,8,22]$. In this work, lymphocutaneous was the most frequent presentation. Our clinical isolate identified as S. globosa (MF948695) had a lymphocutaneous sporotrichosis. This isolate grew well at both $30^{\circ} \mathrm{C}$ and $35^{\circ} \mathrm{C}$ and the growth was restricted at $37^{\circ} \mathrm{C}$; this was the same results reported by Camacho et al. [22]. Treatment for sporotrichosis depends on the clinical manifestation; intolerance to iodine and the high toxicity of amphotericin B limits its use. In the last decades, azole derivatives have been the most effective drugs [23]. Antifungal susceptibility testing varies substantially in reports of in vitro susceptibility from human clinical isolates. We documented susceptibility of the in vitro profile of Sporothrix schenckii complex with molecular identification from China, Japan, Iran, Brazil, and Argentina $[5,9,21,22,24,25]$. In the present study, we evaluated nine antifungal agents against the mycelial phase of $S$. schenckii complex and showed that terbinafine was the most effective drug with a low MIC, while fluconazole was less active; this was comparable to other studies [9,25-27]. Recently Cordoba et al. described similar results for S. schenckii and S. globosa in mycelial phase in Argentina [25]. The behavior of $S$. globosa was equal to other isolates in this study.

\section{Conclusions}

The major species involved in human sporotrichosis are S. schenckii, S. brasiliensis, and S. globosa of diverse geographic origin. Sporotrichosis is common in regions of Latin America with tropical climates. In Mexico, it is a relevant mycosis, mainly in farmers who work with a variety of vegetation [7]. S. schenckii has revealed a high genetic diversity and a recent population expansion process, while S. globosa and S. brasiliensis has shown a rapid clonal distribution [8]. The isolates 
studied in this paper revealed a high degree of genotypic variability among S. schenckii sensu stricto isolates. Based on geographic origin, S. schenckii complex have a wide geographical distribution in our country. Our study showed there was no significant difference in the antifungal in vitro susceptibility among Sporothrix species, including S. globosa in filamentous phase. This study of S. globosa represents the first report of a clinical isolate from Northern Mexico.

Author Contributions: O.C.R. conceived and designed the experiments; A.B. enrolled patients from their respective institutes; C.C. and R.d.J.T.-R. performed the experiments, R.G.-A. performed the phylogenetic analysis; G.M.G. participate in clinical samples collection. All authors read and approved the final manuscript.

Funding: No funding was received for this study.

Acknowledgments: We thank Sergio Lozano for his review of the manuscript.

Conflicts of Interest: The authors declare no conflict of interest.

\section{References}

1. Oliveira, M.M.; Almeida-Paes, R.; Gutierrez-Galhardo, M.C.; Zancope-Oliveira, R.M. Molecular identification of the Sporothrix schenckii complex. Rev. Iberoam. Micol. 2014, 31, 2-6. [CrossRef] [PubMed]

2. Chakrabarti, A.; Bonifaz, A.; Gutierrez-Galhardo, M.C.; Mochizuki, T.; Li, S. Global epidemiology of sporotrichosis. Med. Mycol. 2015, 53, 3-14. [CrossRef] [PubMed]

3. Rodrigues, A.M.; de Melo Teixeira, M.; de Hoog, G.S.; Pacheco Schubach, T.M.; Pereira, S.A.; Fernandes, G.F.; Lopes Bezerra, L.M.; Felipede Camargo, M.S.; de Camargo, Z.P. Phylogenetic analysis reveals a high prevalence of Sporothrix brasiliensis in feline sporotrichosis outbreaks. PLoS Negl. Trop. Dis. 2013, 7, e2281. [CrossRef] [PubMed]

4. Yu, X.; Wan, Z.; Zhang, Z.; Li, F.; Li, R.; Liu, X. Phenotypic and molecular identification of Sporothrix isolates of clinical origin in Northeast China. Mycopathologia 2013, 176, 67-74. [CrossRef] [PubMed]

5. Suzuki, R.; Yikelamu, A.; Tanaka, R.; Igawa, K.; Yokozeki, H.; Yaguchi, T. Studies in Phylogeny, Development of Rapid IdentificationMethods, Antifungal Susceptibility, and Growth Rates of Clinical Strains of Sporothrix schenckii Complex in Japan. Med. Mycol. J. 2016, 57, E47-E57. [CrossRef] [PubMed]

6. Zhang, Y.; Hagen, F.; Stielow, B.; Rodrigues, A.M.; Samerpitak, K.; Zhou, X.; Feng, P.; Yang, L.; Chen, M.; Deng, S.; et al. Phylogeography and evolutionary patterns in Sporothrix spanning more than 14000 human and animal case reports. Persoonia 2015, 35, 1-20. [CrossRef] [PubMed]

7. Mesa-Arango, A.C.; Del Rocio Reyes-Montes, M.; Perez-Mejia, A.; Navarro-Barranco, H.; Souza, V.; Zuniga, G.; Toriello, C. Phenotyping and genotyping of Sporothrix schenckii isolates according to geographic origin and clinical form of Sporotrichosis. J. Clin. Microbiol. 2002, 40, 3004-3011. [CrossRef] [PubMed]

8. Rangel-Gamboa, L.; Martinez-Hernandez, F.; Maravilla, P.; Flisser, A. A population genetics analysis in clinical isolates of Sporothrix schenckii based on calmodulin and calcium/calmodulin-dependent kinase partial gene sequences. Mycoses 2018. [CrossRef] [PubMed]

9. Ottonelli Stopiglia, C.D.; Magagnin, C.M.; Castrillon, M.R.; Mendes, S.D.; Heidrich, D.; Valente, P.; Scroferneker, M.L. Antifungal susceptibilities and identification of species of the Sporothrix schenckii complex isolated in Brazil. Med. Mycol. 2014, 52, 56-64. [CrossRef] [PubMed]

10. Marimon, R.; Gene, J.; Cano, J.; Trilles, L.; Dos Santos Lazera, M.; Guarro, J. Molecular phylogeny of Sporothrix schenckii. J. Clin. Microbiol. 2006, 44, 3251-3256. [CrossRef] [PubMed]

11. Bonifaz, A.; Tirado-Sanchez, A.; Paredes-Solis, V.; Cepeda-Valdes, R.; Gonzalez, G.M.; Trevino-Rangel, R.J.; Fierro-Arias, L. Cutaneous disseminated sporotrichosis: Clinical experience of 24 cases. J. Eur. Acad. Dermatol. Venereol. 2018, 32, e77-e79. [CrossRef] [PubMed]

12. Marimon, R.; Cano, J.; Gene, J.; Sutton, D.A.; Kawasaki, M.; Guarro, J. Sporothrix brasiliensis, S. globosa, and S. mexicana, three new Sporothrix species of clinical interest. J. Clin. Microbiol. 2007, 45, 3198-3206. [CrossRef] [PubMed]

13. Espinel-Ingroff, A.; McGinnis, M.R.; Pincus, D.H.; Goldson, P.R.; Kerkering, T.M. Evaluation of the API 20C yeast identification system for the differentiation of some dematiaceous fungi. J. Clin. Microbiol. 1989, 27, 2565-2569. [PubMed] 
14. John, H.R.; Barbara, D.A.; David, A.; Beth, A.S.; Steven, D.B.; Vishnu, C. M38-A2: Reference Method for Broth Dilution Antifungal Susceptibility Testing of Filamentous Fungi, Approved Standard, 2nd ed.; Clinical and Laboratory Standards Institute: Wayne, PA, USA, 2002; Volume 28.

15. Gonzalez, G.M.; Rojas, O.C.; Bocanegra-Garcia, V.; Gonzalez, J.G.; Garza-Gonzalez, E. Molecular diversity of Cladophialophora carrionii in patients with chromoblastomycosis in Venezuela. Med. Mycol. 2013, 51, 170-177. [CrossRef] [PubMed]

16. O’Donnell, K.; Nirenberg, H.I.; Aoki, T.; Cigelnik, E. A Multigene phylogeny of the Gibberella fujikuroi species complex: Detection of additional phylogenetically distinct species. Mycoscience 2000, 41, 61-78. [CrossRef]

17. McWilliam, H.; Li, W.; Uludag, M.; Squizzato, S.; Park, Y.M.; Buso, N.; Cowley, A.P.; Lopez, R. Analysis Tool Web Services from the EMBL-EBI. Nucleic Acids Res. 2013, 41, W597-W600. [CrossRef] [PubMed]

18. Saitou, N.; Nei, M. The neighbor-joining method: A new method for reconstructing phylogenetic trees. Mol. Biol. Evol. 1987, 4, 406-425. [CrossRef] [PubMed]

19. Tamura, K.; Stecher, G.; Peterson, D.; Filipski, A.; Kumar, S. MEGA6: Molecular Evolutionary Genetics Analysis version 6.0. Mol. Biol. Evol. 2013, 30, 2725-2729. [CrossRef] [PubMed]

20. Madrid, H.; Cano, J.; Gene, J.; Bonifaz, A.; Toriello, C.; Guarro, J. Sporothrix globosa, a pathogenic fungus with widespread geographical distribution. Rev. Iberoam. Micol. 2009, 26, 218-222. [CrossRef] [PubMed]

21. Zhao, L.; Cui, Y.; Zhen, Y.; Yao, L.; Shi, Y.; Song, Y.; Chen, R.; Li, S. Genetic variation of Sporothrix globosa isolates from diverse geographic and clinical origins in China. Emerg. Microbes. Infect. 2017, 6, e88. [CrossRef] [PubMed]

22. Camacho, E.; Leon-Navarro, I.; Rodriguez-Brito, S.; Mendoza, M.; Nino-Vega, G.A. Molecular epidemiology of human sporotrichosis in Venezuela reveals high frequency of Sporothrix globosa. BMC Infect. Dis. 2015, 15, 94. [CrossRef] [PubMed]

23. Kohler, L.M.; Hamdan, J.S.; Ferrari, T.C. Successful treatment of a disseminated Sporothrix schenckii infection and in vitro analysis for antifungal susceptibility testing. Diagn. Microbiol. Infect. Dis. 2007, 58, 117-120. [CrossRef] [PubMed]

24. Mahmoudi, S.; Zaini, F.; Kordbacheh, P.; Safara, M.; Heidari, M. Sporothrix schenckii complex in Iran: Molecular identification and antifungal susceptibility. Med. Mycol. 2016, 54, 593-599. [CrossRef] [PubMed]

25. Cordoba, S.; Isla, G.; Szusz, W.; Vivot, W.; Hevia, A.; Davel, G.; Canteros, C.E. Molecular identification and susceptibility profile of Sporothrix schenckii sensu lato isolated in Argentina. Mycoses 2018. [CrossRef] [PubMed]

26. Kohler, L.M.; Soares, B.M.; de Assis Santos, D.; Da Silva Barros, M.E.; Hamdan, J.S. In vitro susceptibility of isolates of Sporothrix schenckii to amphotericin B, itraconazole, and terbinafine: Comparison of yeast and mycelial forms. Can. J. Microbiol. 2006, 52, 843-847. [CrossRef] [PubMed]

27. Gremiao, I.D.; Menezes, R.C.; Schubach, T.M.; Figueiredo, A.B.; Cavalcanti, M.C.; Pereira, S.A. Feline sporotrichosis: Epidemiological and clinical aspects. Med. Mycol. 2015, 53, 15-21. [CrossRef] [PubMed]

(C) 2018 by the authors. Licensee MDPI, Basel, Switzerland. This article is an open access article distributed under the terms and conditions of the Creative Commons Attribution (CC BY) license (http://creativecommons.org/licenses/by/4.0/). 